\title{
Lidil
}

Revue de linguistique et de didactique des langues

$56 \mid 2017$

Grammaires et littéracies

\section{André Petitjean (dir.), Didactiques du français et de la littérature}

Crem/Université de Lorraine, coll. « Recherches textuelles », nº 14, 2016, $617 \mathrm{p}$.

\section{Carole Calistri}

\section{(2) OpenEdition}

\section{Journals}

Édition électronique

URL : http://journals.openedition.org/lidil/4711

DOI : $10.4000 /$ lidil. 4711

ISSN : 1960-6052

Éditeur

UGA Éditions/Université Grenoble Alpes

Édition imprimée

ISBN : 978-2-37747-024-2

ISSN : $1146-6480$

Référence électronique

Carole Calistri, «André Petitjean (dir.), Didactiques du français et de la littérature », Lidil [En ligne], 56 |

2017, mis en ligne le 01 novembre 2017, consulté le 23 septembre 2020. URL : http://

journals.openedition.org/lidil/4711 ; DOI : https://doi.org/10.4000/lidil.4711

Ce document a été généré automatiquement le 23 septembre 2020 .

(C) Lidil 


\section{André Petitjean (dir.), Didactiques du français et de la littérature}

Crem/Université de Lorraine, coll. « Recherches textuelles », nº 14, 2016, $617 \mathrm{p}$.

\section{Carole Calistri}

\section{RÉFÉRENCE}

André Petitjean (dir.), Didactiques du français et de la littérature, Crem/Université de Lorraine, coll. « Recherches textuelles », $n^{\circ} 14,2016,617$ p.

1 La sélection d'articles du colloque « 40 ans de Pratiques » fait un point sur les difficultés de la discipline scolaire "français " : crise de la transmission, de la légitimité de son enseignement en regard des mutations rapides de tous ordres (A. Boissinot), crise du recrutement, que l'élargissement du périmètre disciplinaire et la professionnalisation accrue du concours peinent à contenir (A. Vinet). Tous les problèmes sont posés : de l'autonomisation de la didactique au décrochage des élèves en passant par l'analyse heuristique des relations complexes entre prescriptions, recommandations, pratiques et appropriations (Y. Reuter).

2 L'ouvrage atteste des combats gagnés contre les idées reçues - illusion du langage transparent et naturalité - dans l'enseignement du texte théâtral (F. Legoff), de l'ambition développée en didactique de la lecture: lire, puis comprendre, puis interpréter, dans le mouvement d'une ambition toujours plus grande pour des élèves toujours plus jeunes (M.-F. Bishop). Il souligne aussi des avancées, même modestes, comme celle de l'enseignement de la littérature belge en Belgique (F. Châtelain) ou de vraies-fausses victoires, comme celles des paralittératures. Celles-ci ont d'abord été intégrées aux programmes puis diluées dans des objets disciplinaires et en voie, pour partie de classicisation, pour partie d'exclusion nette pour ce qui est de la culture populaire (N. Denizot) ; on aborde aussi la didactisation de l'écriture littéraire, passée de l'utopie à l'atopie (N. Biagioli). 
Ce bilan est aussi l'occasion de faire un état des lieux concernant les visées de la didactique du français : il s'agit d'outiller les enseignants pour analyser l'observation, la compréhension et la remédiation des difficultés des élèves (M. Laparra). Mais l'ouvrage fait place également aux spécialités de la didactique du français : par exemple à la question du français sur objectifs universitaires (FOU), à la recherche, pour les auteurs d'une généralisibilité nocive (A. Prunet et $\mathrm{D}$. Toussaint); ou à la réflexion éthique dans l'étude des textes (R. Michel) ou encore à la tension littéracie/oralité (J.-M. Privat). On y examine aussi les rapports entre la didactique du français et d'autres didactiques. On voit les bénéfices générés en termes d'apprentissage, par une double approche en LP de textes littéraires (M.-F. Rossignol). On y voit aussi l'intérêt d'une didactique des pratiques discursives dans sa relation avec les arts (J.-C. Chabanne). Dans ce cas, on risque toujours un malentendu socio-cognitif, si les professeurs voient de l'art là où les élèves ne voient que difficulté (M.-S. Claude). Et demeure l'inquiétude concernant le rapport à la didactique des enseignants belges du secondaire (J.-L. Dumortier et J. Van Beveren) pour qui un écart se creuse entre chercheurs et praticiens.

4 Dans ses perspectives finales, l'ouvrage dresse la liste de chantiers déjà entamés, qu'il s'agisse d'une vision désormais curriculaire de l'enseignement de la littérature (J.L. Dufays et M. Brunel), des extensions du champ littéraire (mediaculture), des approches historique, descriptive et professionnelle prises en compte (S.Ahr), des influences entre lecture, écriture et interprétation (B. D. Parmentier), du succès mitigé d'artefacts numériques lors de discussions à visée littéraire (S. Genre et J.-C. Chabanne). Dans cette catégorie, l'inscription institutionnelle des ateliers d'écriture fait entrevoir le commencement de la liaison souhaitée entre enseignement de la littérature et enseignement de la pratique littéraire (C. Oriol-Boyer et C. Duminy-Sauzeau); tandis que l'étude du Point de vue qui ouvre à l'altérité, augmente la compréhension des textes et contribue au vivre ensemble (A. Rabatel), non négligeable en nos temps.

Naturellement, les chantiers à entamer sont évoqués; dans Pratiques il n'y pas de «sujet lecteur » (B. Louichon) : il reste à s'intéresser à l'apprenti-lecteur, aux apports possibles d'un accompagnement de l'imaginaire, à l'éducation aux droits du texte (A. PerrinDoucey). Pour cela, éduquer à une posture empathique (I. Artigues) reste un chantier à construire. On notera pour finir l'absence d'une didactique de la poésie aux bénéfices prometteurs - dépassement du clivage littérature/langue, apports en narratologie et ascenseur social - qui reste à promouvoir dans le projet politique comme dans celui des chercheurs (M. Favriaud).

Dans cette traversée de Pratiques (et peut-être aussi de la didactique du français), tout ce qui précède ne peut faire oublier les mutations du praxéologique au méta, du militant à l'universitaire (J.-P. Benoît) et, à l'arrivée, la place finalement manquante de l'engagement politique (Y. Reuter). 


\section{AUTEURS}

\section{CAROLE CALISTRI}

Université Nice Sophia Antipolis, ESPE de l'académie de Nice, LINE 